\title{
Ancient Human Bones, Contributions from the Sem
}

\author{
G.Baggieri $^{1}$, G. Guida ${ }^{2}$ \\ ${ }^{1}$ Soprintendenza al Museo Nazionale Etnografico Preistorico L. Pigorini - Roma Ministero per i Beni e le Attività Culturali. \\ E-mail: gaspare.baggieri@beniculturali.it \\ 2 Istituto Superiore per la Conservazione - Roma Ministero per i Beni e le Attività Culturali
}

KEYWORDS: bone, SEM, pictures.

\section{Introduction}

We collected more than 200 images of the structure of ancient bones (VI-VII century), at different magnifications. For the most part they are small fragments of flat bones extracted from about twenty samples coming from the Early Medieval Necropolis of Romans d'Isonzo (Gorizia Italy). Here we present some of the images from the study. Observations were made on the base of the following books and authors:A.A.V.V., Longobardi a Romans d'Isonzo, itinerario attraverso le tombe altomedievali, Catalogo mostra Palazzo Economo, Soprintendenza Archeologica e per i Beni AAAS del FriuliVenezia Giulia, Trieste, 1989; G. Baggieri (a cura di), La necropoli di San Mauro a Cividale, aspetti antropologici, Soprintendenza Archeologica e per i BAAS del Friuli Venezia Giulia, Roma, 2001; G. Baggieri, Prime osservazioni sulle dentature degli inumati della necropoli di Romans d'Isonzo, cenni di morfologia generale, "I Scussòns", Roma, 2006; F. Bartoli,A. Bacci, Regime alimentare nei gruppi umani del passato, in F. Mallegni, B. Lippi, “Non Omnis Moriar", CISU, Roma, 2009; G.Guglielmi, F.Urbano, Diagnostica radiologica e densitometrica, in Riv. It. Ost. E Gin. n.5 del 2005; P. Carnot, E. Lancereaux, M. Letulle, R.Wurtz, Intossicazioni, UTET, Torino, 1908; L. Giuntini, E.Agrifoglio, Manuale di ortopedia e traumatologia, SEU, Roma, 1976; D.B. Hanson, J.E. Buikstra, Histomorfological Alteration in Buried Bone from the Lower Illinois Valley: Implication for Paleodietary Research, J.Archaeol. Scien., n. 14, pp. 549-563, 1987; J. Jowsey, Metabolic Diseases of Bone,W.B. Saunders Co., Philadelphia, 1977; L. Lichtenstein, Malattie delle ossa e delle articolazioni,Verduci, Roma, 1976; R.B. Martin, D.B. Burr, Structure, Function and Adaptation of Compact Bone, Raven Press, New York, 1989; F. H Netter,Atlante di anatomia - apparato muscolo scheletrico, Vol. 8, Ciba, Origgio - Varese, 1987; D.J. Ortner, Microscopic and Molecular Biology of Human Compact Bone, an Anthropological Perpesctive, Yrbk Phis. Anthropol., n. 20, pp. 35-44, 1976; M. Schultz, Paleohistopathology of Bone: a New Approach to the Study of Ancient Diseases, Supp. 33,American Journal of Physical Anthropologists vol. 44, 2001; P. Schwartz, M. Schultz, Post-Mortem Destruction of Archaeological Skeletal Material Caused by Insects.A
Biol., Suppl. n. 45, pp. 117, 1994; S.D. Stout, Histological Structures and its Preservation in Ancient Bone, Curr. Anthropol., n. 199, pp.601-604, 1987.

\section{Discussion, captions and conclusion}

The observation of the fragments was performed dry without any treatment, except for the cleaning of the bones, and allowed us to unequivocally recognize some physiological deteriorations of these human bones. Some of these decays are induced by environmental conditions while others are provoked by the natural and temporal process of bone ageing which is due to a process that, as we all know, always occurs post-mortem (except for mummified or treated corpses).

We can infer valuable information about the diagenesis of the bone, from the analysis of the microstructure. These observations give us a correct indication about the most important contaminants and on the aptitude of the bone to act as an absorbing sponge.

I. Magnification of two osteons with their concentric lamellar system which appears to be disrupted; arrangement of the interstitial lamellae, in the fundamental system. Below, we can also note some phenomena of osteon ossification (Signal A = QBSD Mag. 300x).

2. Thick structure of canals and tubules. It is possible to note a disrupted patent hole which is inordinately surrounded by the interstitial lamellae of the fundamental substance. On the right side, a small hole which is probably due to a Volkmann canal (Signal A = QBSD Mag. 300x).

3. Interesting image at high magnification which shows the lamellar structure seen in transversal section. It is a tubular-canalicular shaped structure dedicated to the blood spraying, and to oxygen transport to the cells which fill the bone (Signal A = QBSD Mag. 800x).

4. Transitional area of the compact bone. Transversal section with bone remodelling in the progress of lamellar apposition. Below (on the center), tubular system (Signal A = QBSD Mag. 500x).

5. A possible Howship lacuna in the compact, thick bone. There is a slightly shiny perimeter around the hole, from which the imprints of the ramifications (which are characteristic of the Howship lacunae) spread out. 


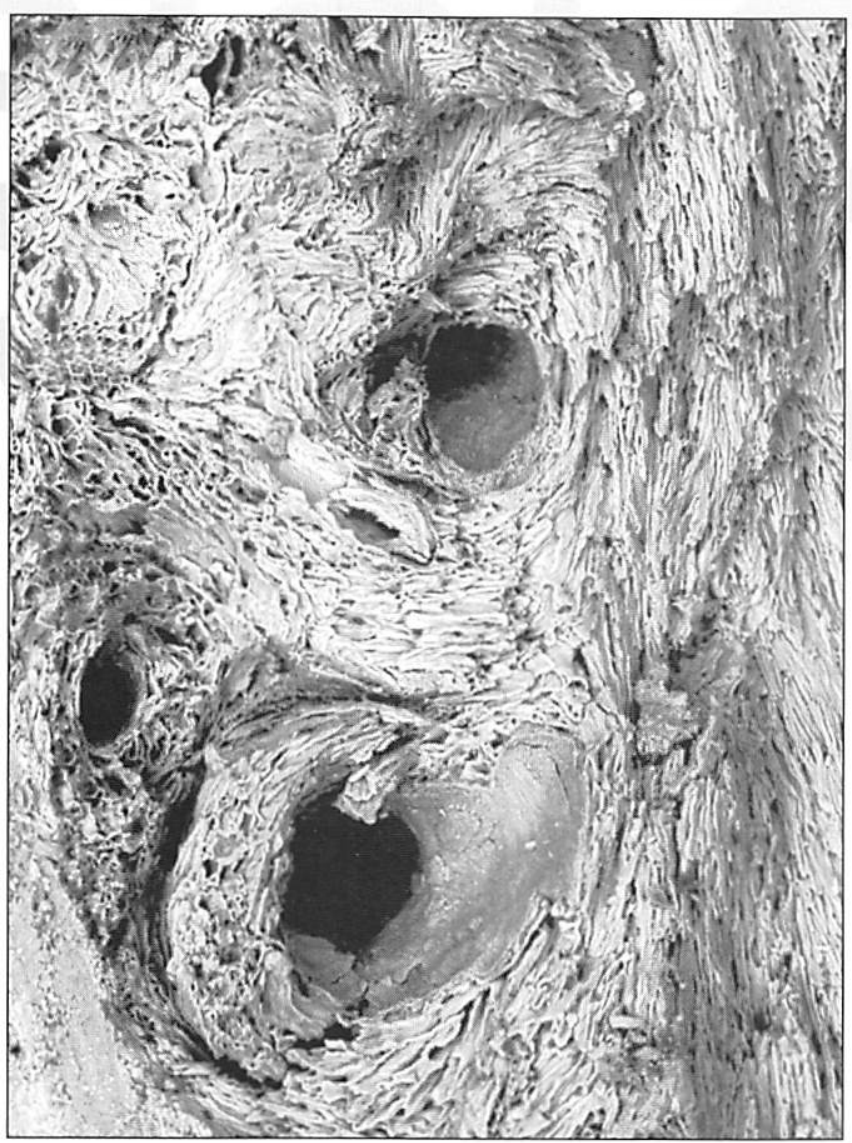

Fig. 1

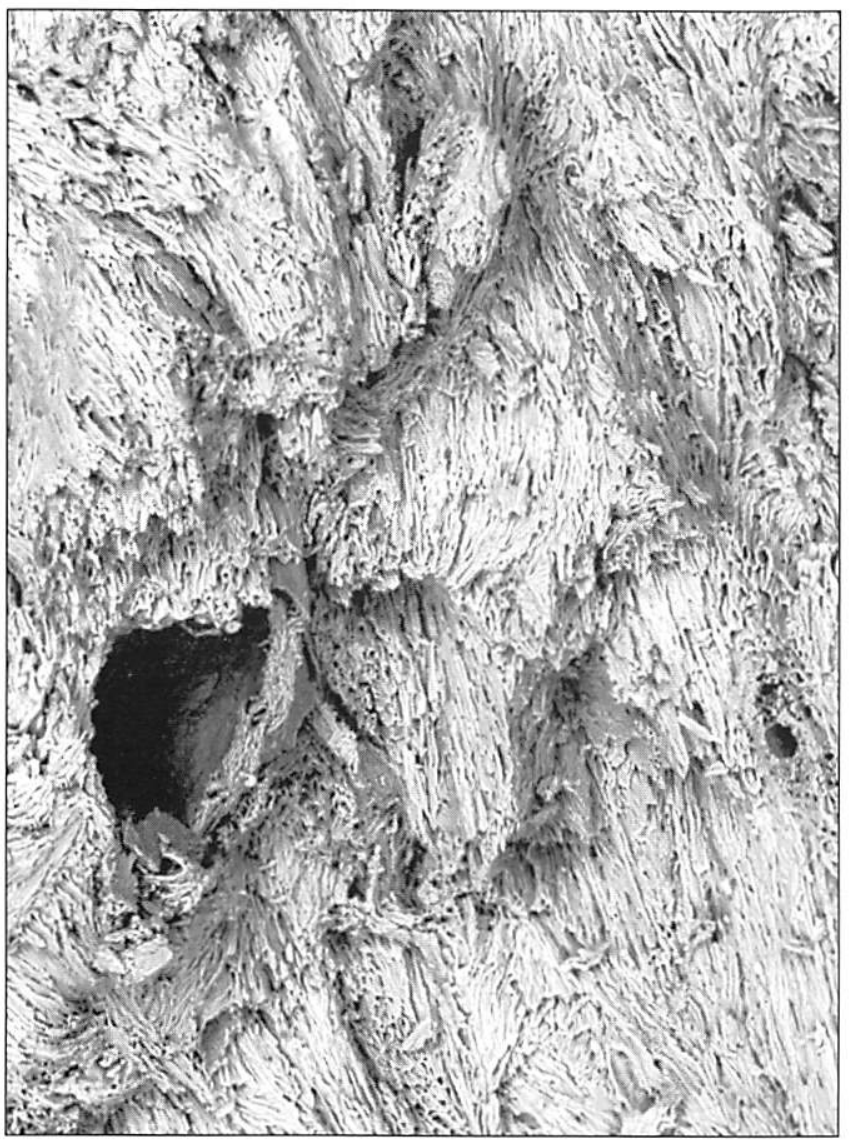

Fig. 2

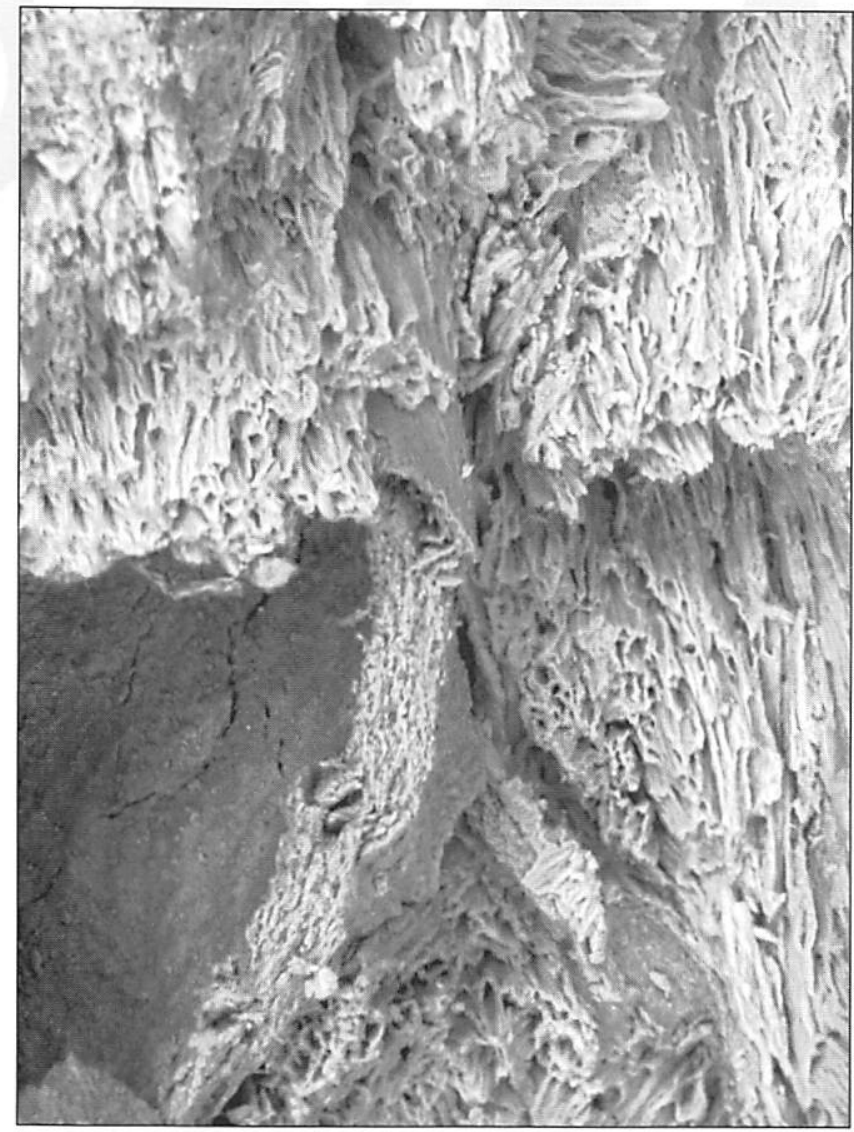

Fig. 3

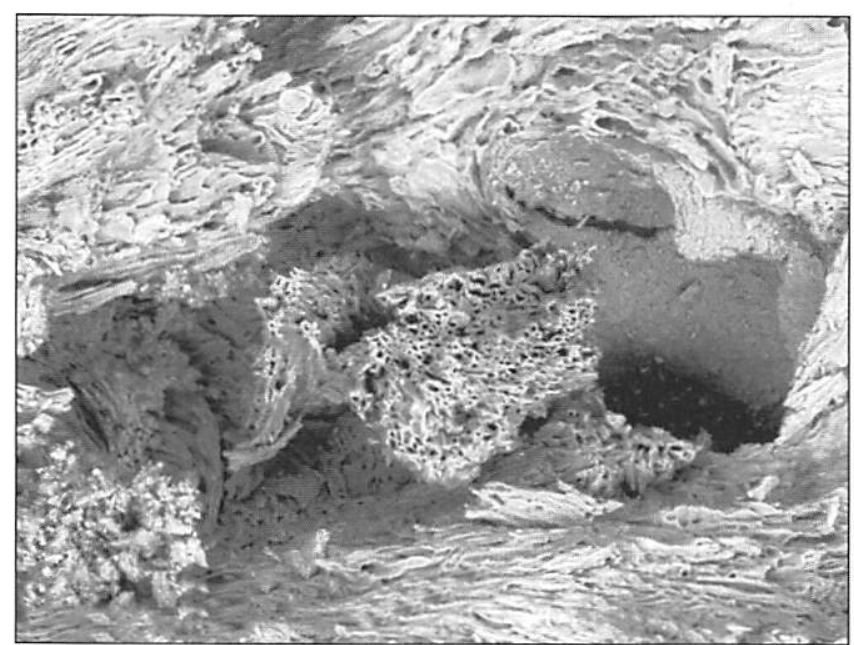

Fig. 4

These offshoots are likely the result of the interface on the bone. We can see, inter alia, what must have originally been the brush-shaped edge of the imprints left by the osteoclast on the bone surface (Signal A = QBSD Mag. 2.880x).

6. Architecture of the trabeculae with bone remodeling in the internal walls, the latter delineates the marrow spaces. Below at the right side, two osteons of the Haversian system. The striae are the result of the cutting blade (Signal A = QBSD Mag. 100x).

7. A secondary osteon close to a marrow space. We can notice the limit of the compact and the spongy bone. 


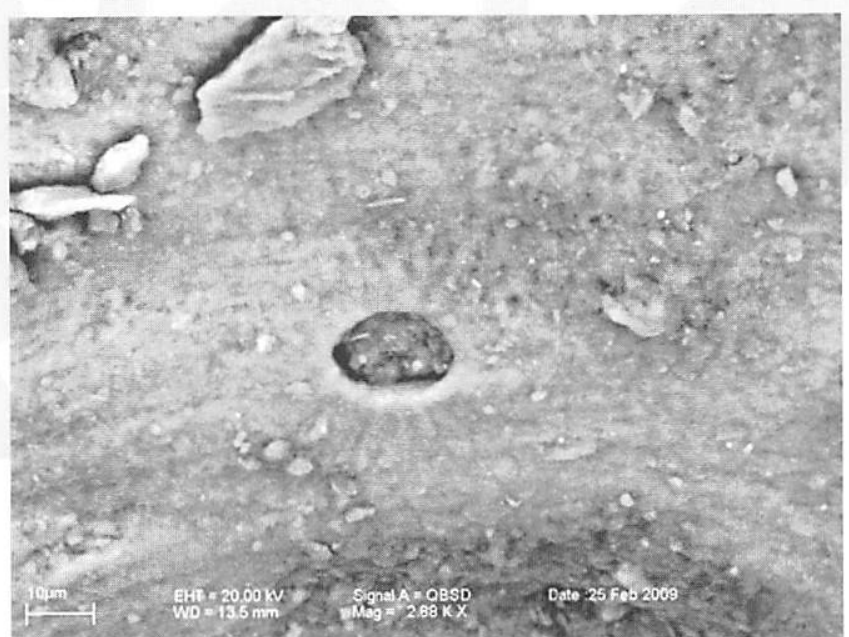

Fig. 5

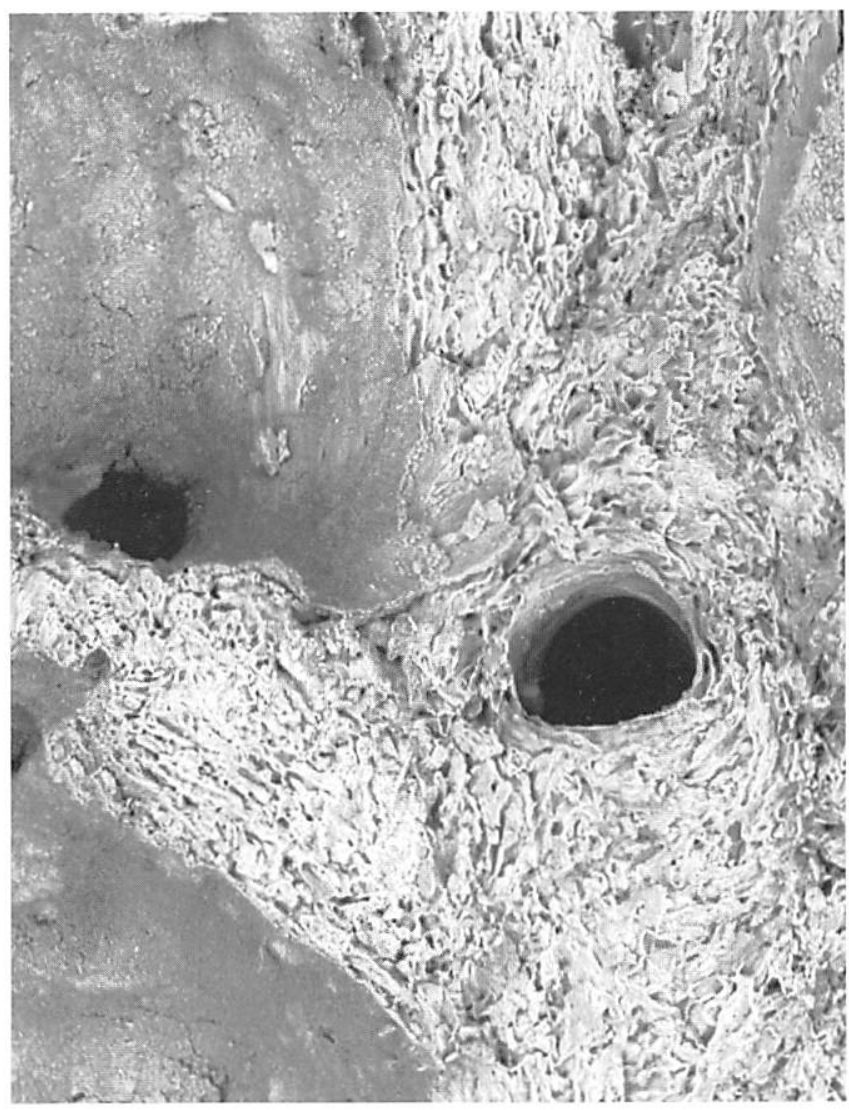

Fig. 7

The lamellae are subverted and their circularity around the osteon is inordinately distributed. The structure of the dissected bone is made up of interwoven lamellae. It is possible to recognize the tubular canaliculi belonging to the nutritive apparatus (Signal A = QBSD Mag. 383x).

8. Detail of the osteonic dynamism. We can notice the systems (subverted) of the interstitial and concentric lamellae (Signal A = VPSE Mag. 200x).

9. Detail of two bone connections within a hollow space (recognizable for its breadth and depth). The whole complex of the bone surface appears to be smooth, similar to melted wax. There is no presence of any lamellar dynamism (Signal A = QBSD Mag. 150x).

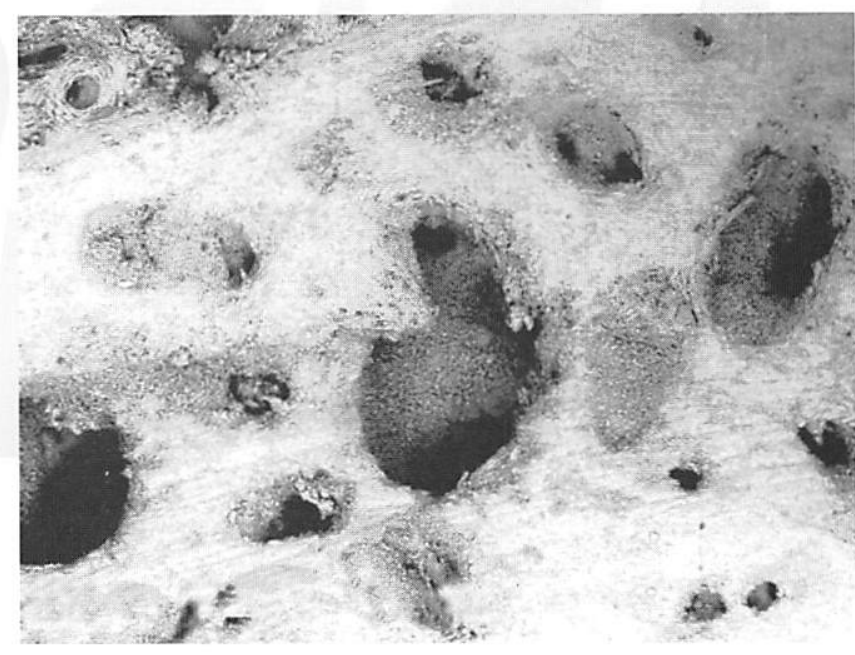

Fig. 6

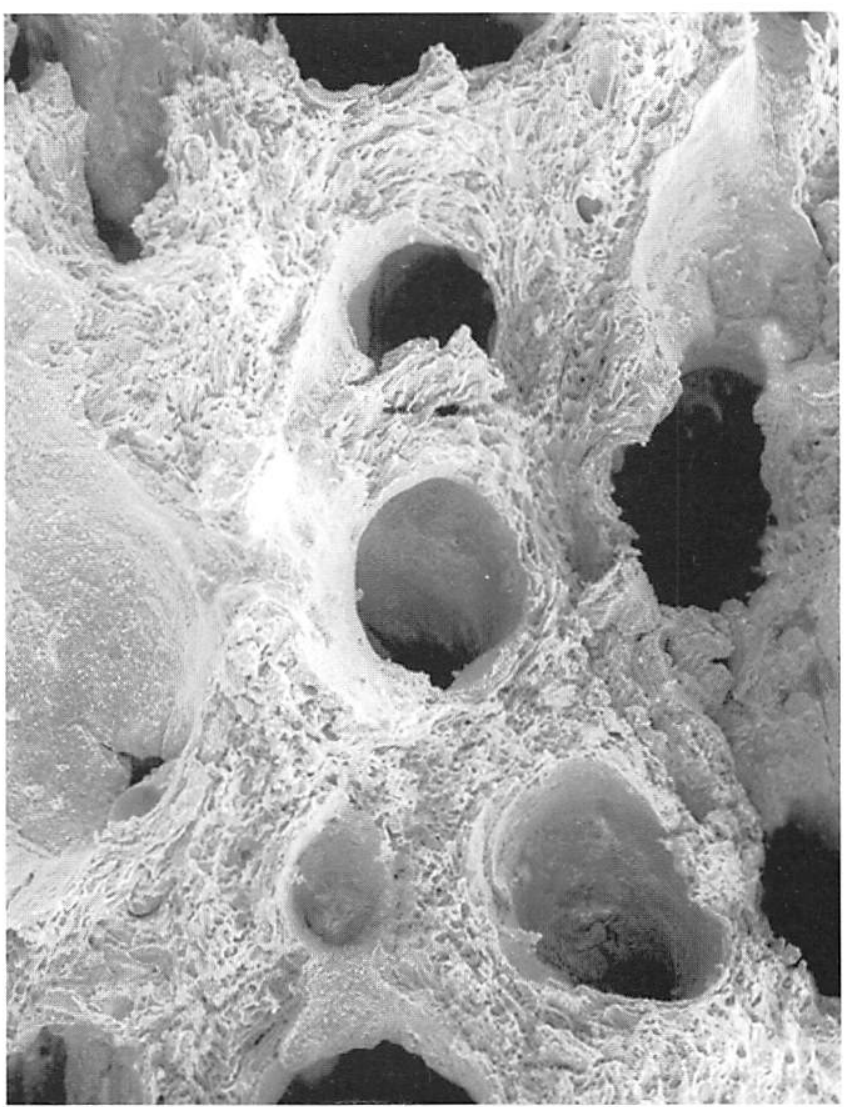

Fig. 8

10. Osteons which open up within a medullary cavity without any evident arrangement of the concentric lamellae.We can see some empty spaces of the bone structure, which are very likely the results of the spaces which belonged to the osteocytes (Signal A = QBSD Mag. 300x).

\section{Acknowledgments}

A special thank goes to "I Scussòns", the Cultural Association which allowed the publication of the scientific monograph. 


\section{Ancient Human Bones, Contributions from the Sem}
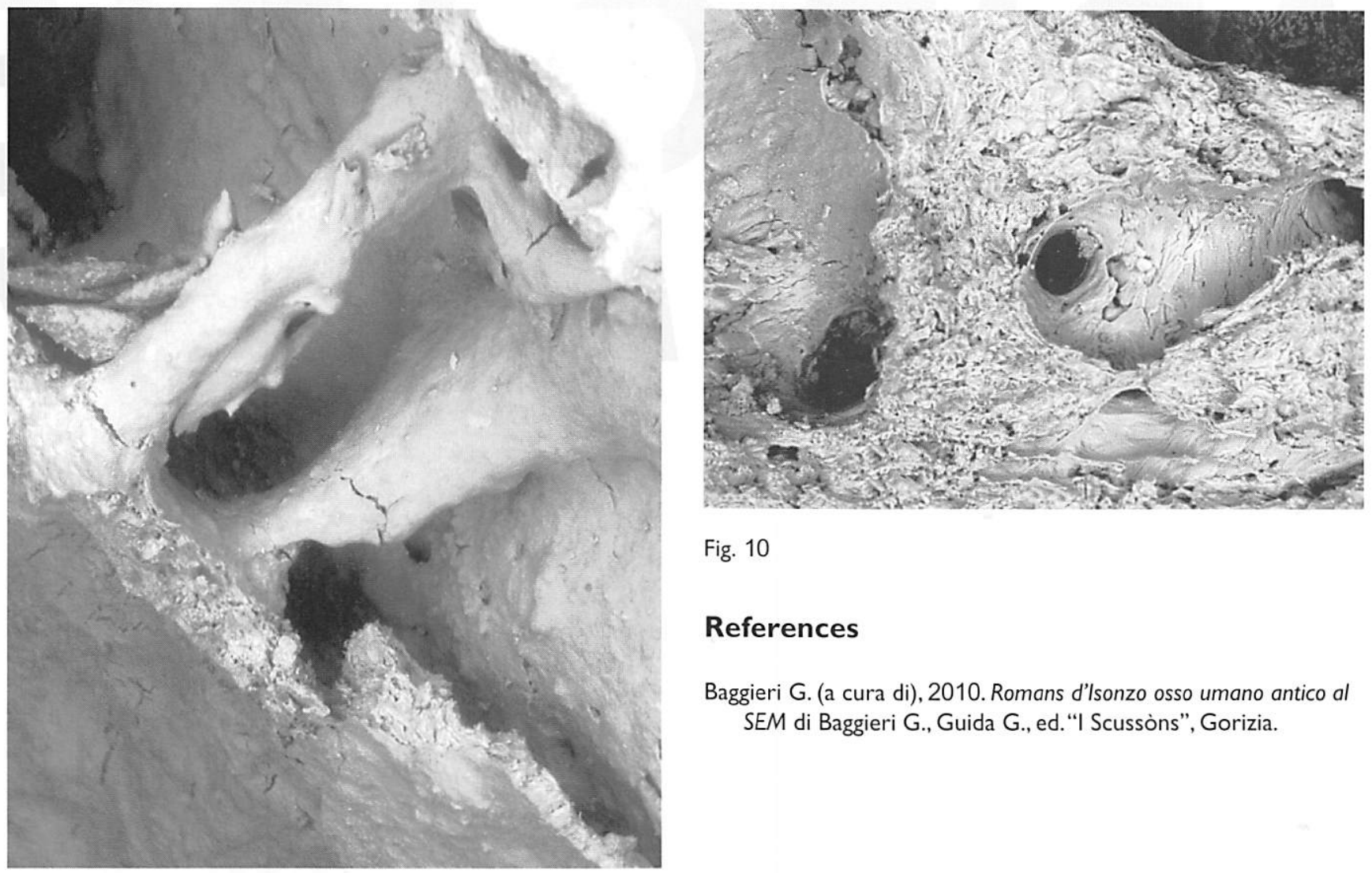

Fig. 10

\section{References}

Baggieri G. (a cura di), 2010. Romans d'lsonzo osso umano antico al SEM di Baggieri G., Guida G., ed. "I Scussòns”, Gorizia.

Fig. 9 